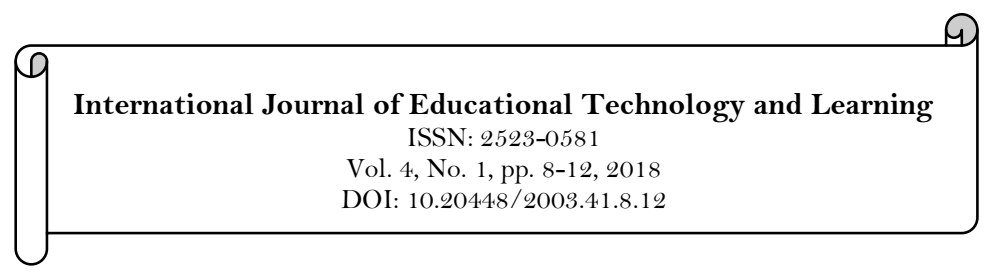

\title{
The Didactics of Bilingual Education: Disciplinary Teaching and Language
}

\author{
Georges Faustin Koumje ${ }^{1}$ \\ 'École Normale Supérieure, University of Yaoundé 1, Cameroon. \\ Email: faustingeorges8@gmail.com
}

\begin{tabular}{|c|c|}
\hline stract & \\
\hline $\begin{array}{l}\text { The didactics of teaching and language are pioneer subjects to be } \\
\text { considered, when learning any particular language. This article puts } \\
\text { to light the specificity of the learning process through different } \\
\text { approaches such as: the comprehensive input and the balance } \\
\text { approach. The theory of joint action, which constitutes the } \\
\text { theoretical frame of reference for this work, will allow us to grasp } \\
\text { two essential aspects of the relationship between disciplinary } \\
\text { knowledge and language. The findings showed that there is a close } \\
\text { interdependence of disciplinary knowledge and language. The social } \\
\text { function of transmitting knowledge of language is now universally } \\
\text { accepted in the scientific community: knowledge is acquired through } \\
\text { participation in mediated experiences in communication with an } \\
\text { expert. The acquisition of language and the acquisition of } \\
\text { disciplinary knowledge are, however, treated as two distinct } \\
\text { domains, as if thought were a purely mental object without a } \\
\text { necessary relation to language. }\end{array}$ & $\begin{array}{l}\text { Licensed: } \\
\text { This work is licensed under a } \\
\text { Creative Commons Attribution } \\
\text { 4.0 License. } \\
\text { Publisher: } \\
\text { Scientific Publishing Institute }\end{array}$ \\
\hline
\end{tabular}

\section{Introduction}

In Cameroon, the teaching of a school subject in a second language called bilingual education is mainly practiced for teaching in the national languages and in Cameroonian classrooms. This teaching has the particularity of aiming at the appropriation of two objects of knowledge, disciplinary knowledge and the second language. Its didactic device is generally defined by the non-linguistic discipline. Unlike language classes, language is not the central parameter determining the organization and progression of teaching. It is at the service of disciplinary teaching.

In research, the specificity of the learning process is apprehended through different approaches. (Krashen, 1977; Krashenp, 1981; Krashens, 1978) emphasizes the importance of comprehensible input and advocates unconscious appropriation of the language. (Long, 1981; Longp, 1985; Longs, 1983) emphasizes the importance of negotiating input in order to make it understandable. (Swain, 1985; Swains, 1995) understandable output hypothesis emphasizes the need to actively use language. Beyond their differences, these conceptions all agree to privilege linguistic aspects to the detriment of disciplinary learning. It follows a somewhat paradoxical situation: while the practice focuses on the disciplinary subject, the research isolates and interrogates a single element in the service of its learning, namely the language. To overcome this piecemeal and piecemeal approach, it is necessary to construct a theory that integrates all the parameters affecting the learning process in order to understand all the dynamics at work in the teaching and learning systems. It will also help to better understand the role of language in this context.

To illustrate this approach, our methodological choices will initially be specified. They will then be linked to the theory of joint action, which constitutes the theoretical frame of reference for this work. Finally, it will allow us to grasp two essential aspects of the relationship between disciplinary knowledge and language. 


\section{Theoretical Considerations}

Bilingual education has been practiced for many years without having a real theory. The practice needs to be captured, streamlined and explained. It must be grasped in its specificity. This is the objective of the theory to be constructed, which will be based directly on the observation of activities aimed at the appropriation of two objects of knowledge. In essence, it will be trans-discipline since it must integrate all the subjects that can be taught in a second language. Multi discipline implies the ability to accommodate various methodologies. In other words, it will be an extension of the work carried out so far in the various didactics of the disciplines. It will be based on a common denominator for all disciplines able to integrate all the possible elements: the knowledge to acquire. Modeling its process of appropriation implies to consider all the parameters acting in its construction.

The new direction proposed here is based on the theory of joint action developed by Sensevy and Mercier (2007) as a result of work in mathematics didactics. Centered on disciplinary knowledge and the factors conditioning its appropriation, it considers the collective construction of knowledge in institutions. School education represents an institutionalized form of knowledge transfer. It is based on planned processes aimed at achieving a goal that is the construction and appropriation of knowledge based on structured experiences in a social context (Becker-Mrotzek \& Vogt, 2009). Knowledge is born and built according to external factors. He lives in social practices and is acquired by participating in practices. However, learning is not a transfer of ideas, information or emotions from one person to another. Learning is a social process negotiated by the teacher "and" the learner. It is based on communication between the expert and the novice. New knowledge is acquired through listening, reading, speech and writing.

\section{The Theory of Joint Action}

The knowledge taught by so-called non-linguistic disciplines is varied and presupposes mastery of tasks specific to the discipline. Their contents relate to the phenomena of nature, society, history, mathematics, etc. The genesis of this knowledge is not to be found in the educational institution but in the learned communities (Verret, 1975). Scientific knowledge and the functioning of science, however, cannot be faithfully communicated to students. Their complexity effectively conflicts with the cognitive limits of learners. Access to knowledge is then organized in a way adapted to their resources: their migration from one institutional sphere to another is called by epistemologists "didactic transposition". This passage is taken into account by the didactic systems that structure the process of transposition by practicing three subsystems:

- mesogenesis or identification of epistemic content in didactical transactions;

- chronogenesis, which deals with the disposition of the knowledge taught on the time axis, its progression and its evolution;

- the topogenesis that questions the responsibility of the teacher and the student in the construction of knowledge (Sensevy \& Mercier, 2007).

- Mesogenesis helps to understand the role of language in teaching. It raises a number of questions: what are the transposed epistemic contents? How is the common elaboration of a system of meanings articulated through classroom practices? How are particular knowledge objects configured?

To teach new knowledge, the teacher deliberately involves the student in various activities such as solving problems in mathematics. The construction of knowledge is then assisted by an external mediation that directs the activity in progress. This support is characterized not only by the support of the teacher but also by the use of concrete objects (instrumental mediation) and various signs (semiotic mediation). The signs are perceptible traces of the objects of the world. They also exteriorize our mental representations which are thus made perceptible and accessible to others. The study of the objects of knowledge implies to take into account their means of access, in other words, a mental object cannot be approached without evoking its representation.

The language of science uses multiple representations: words, diagrams, graphs, mathematical symbols, and so on. Figures and diagrams can be much more expressive than a descriptive text or a list of formulas. A lot of relevant information is also accessible by body signs. Body language can actually reveal more than a speech or a text. The didactic transposition can draw on a reservoir rich in semiotic means whose use is not subject to free will. What is the specificity of verbal language in this diversity? Two functions seem essential in the construction of knowledge: epistemic function and academic cognitive function.

\section{The Epistemic Function of Language}

Language is more than a social instrument of communication. It participates in the construction of thoughts and knowledge. This hypothesis largely developed in philosophy is also supported by some psychologists and linguists. It asserts that knowledge and language are not two distinct and autonomous domains existing independently of one another:

We contend that the conception of knowledge is something that exists independently of language, and may be coded or made manifest in illusory language. All knowledge is in semiotics, with language in most central; and all representation of knowledge in the first place. Knowledge and meaning are not two distinct phenomena; they are different metaphors for the same phenomenon (Hammond \& Gibbons, 2001). 
If indeed knowledge is anchored in a semiotic system it does not mean that the function of signs is purely mnemonic in the sense that they fix in memory ready-made thoughts for later reuse. On the contrary, they participate in the formation of thoughts by transforming perceptions and experiences into a mental form (Leinfellner, 1965). More precisely, they fix perceived individuals, delimit them, and structure in units of thought (Cassirer, 1922; Cassirers, 1923). Words are sensible signs by which portions of thought come to unity. They organize the multiplicity of phenomena into synoptic units (Kant, 1781). The content of the latter may vary according to the language used which holds or neglects elements of the situation. The formative function is not limited to the word. Our experience is also schematized by grammar. For example, an individual using the linguistic category "substantive" attributes to the observed phenomenon the quality of the individual. The latter is not inherent in the observed object but is the result of an attribution. This is not the fruit of a subjective individual operation. The individual acquires it by virtue of public rules that govern both the choice of linguistic elements that we learn and their use in a given linguistic community. The categories conveyed represent the intellectual work of language which classifies phenomena as an object (the name) or an activity (verb), and which can distinguish by inflection the form of action (notion of agent, patient) in a given context (Slobin, 2003). Sfard (2000) emphasizes the importance of this hypothesis for mathematics: in mathematics we are used to using verbs such as subtract, divide or multiply.

However, as soon as these verbs are replaced by names, the discourse receives a new orientation. We move from an operational approach to a structural focus since the name is characterized by different ontological categories of the verb. Its significance possesses the properties of an object namely: existence, permanence, manipulability. To give a name is to be considered not as a baptism but as an act of conceptualization.

The existence of symbols and the possibility of using them in an abstract way are, for Cassirers (1923) the two factors indispensable to the evolution of reasoning towards scientific thought. The symbol delimits entities whose accessibility makes possible the return of the thought on itself. It is the mediator of thought towards itself; a form of mirror that gives thought the ability to come back on itself. It is the most important instrument for the conquest and construction of a real world of objects. To speak is not first to communicate but to think, to form and to become aware of our own thoughts. This is the reason why the progress of research and construction of concepts has been accompanied by a differentiation of symbolic systems whose primary function is not the denomination of objects or the representation of ready thoughts but the structuring of thought. All rigorous and exact thinking is effectively rooted in symbolism and relies on semiotics. (Cassirers, 1923)

Therefore there is no externality between thought and speech or between the act of thinking, of having ideas and the act of speaking, of making sentences. The idea does not exist before the language; it is formed in him and by him. Language is the place where the thought of man is exercised: thought reasons in language to find and to say oneself.

\section{Academic Cognitive Function}

On an individual level, language is a powerful instrument of cognition but not only. It also ensures the social function of knowledge transmission. The appropriation of new knowledge is based on exchange. Indeed, each discipline has a discursive culture generated by its history and its epistemic needs. Each subject requires various communication skills, such as:

- read and understand informative texts, the structure of which often varies according to the discipline;

- listen to explanations given by the teacher on complex subjects;

- answer questions both orally and in writing;

- present research and study results;

- participate in debates on specific themes (Vollmer, 2009).

For Thürmann (2012) the use of language in the classroom is based on several varieties. He justifies his hypothesis by referring to Bailey and Heritage (2008) and Scarcella (2008) which distinguish the Basic Colloquial Language (BCL), the School Navigational Language (SNL), the Essential Academic Language (EAL) and the Curriculum Content Language (CCL). Little research has been done today on how to use language for teaching and the appropriation of specific knowledge. Yet the dependence of disciplinary learning on verbal communication is beyond doubt.

The disciplines taught in the school institution are distinguished by their way of perceiving and structuring reality. Each discipline also has its logic of action. It determines access to knowledge and language needs. The way of apprehending knowledge compels discursive communication. In history, for example, the construction of knowledge is based on analysis, appreciation of facts and value judgments. Each dimension is related to specific discursive forms: the analysis of historical events is based on the identification and description of facts; the assessment of facts is based on explanation, comparison and argumentation; Value judgments result from argumentation and evaluation (Handro, 2013; Jeismann, 1978).

On the formal level, the various functions translate into more or less complex verbal forms. The comparison can be content with a simple sentence such as " $\mathrm{x}$ is greater than $\mathrm{y}$ " whereas the argument is based, as a rule, on more complex verbal forms. A quantity of information can be organized in the form of texts or 
genres such as reporting, narration, expertise, etc. Genres are more or less conventional discursive and social practices linking a quantity of information in a coherent and structured way. They are not fixed textual and syntactic models transposed according to need in various contexts. The existing forms are adapted to the specificities of the situation. Their mastery involves a semiotic, cognitive and social skill called by Cummins "Cognitive Academic Language Proficiency (CALP)". According to Hallet (2013) four components characterize the discursive genre:

- the epistemological dimension (the way of structuring reality;

- the cognitive schema (the way of representing and modeling knowledge);

- the textual structure (how to organize the signs in order to structure the contents and endow them with a coherent textual form);

- Interactional discursive structure (the way of interacting).

For Hallet (2013) the academic function is an integral part of the disciplinary competence which consists at least of the following three dimensions:

- The network of disciplinary knowledge;

- Disciplinary reasoning and its methodology;

- Communicative and semiotic competence including mastery of discursive genres.

Disciplinary teaching is based on the use of a wide variety of academic genres and functions, the mastery of which determines the understanding, representation and communication of knowledge. Their appropriation is the basis of all school learning. These are basic prerequisites for success in school. However, academic functions are rarely subject to verbalization and explanations in class. Their use as well as their mastery is, as a rule, taken for granted. However, large-scale surveys such as the Third International Mathematics and Science Study (TIMSS), PISA (Program for International Student Assessment) or PIRL (Progress in International Reading Literacy) have clearly established the cognitive or language difficulties that discourse conventions and models of language use in class. Thematizing the cognitive and linguistic requirements in each subject therefore seems essential to access information and cognitive operations, especially since verbal means are today the subject of a particular learning like the bilingual classes. The teacher will then be asked, during the preparation of his courses, to ask himself the following questions: what are the knowledge, the linguistic means and the kinds necessary for the realization of a specific activity? Are these means available to the learner? Are there specific measures that support them on a cognitive or linguistic level such as visual aids (graphics, tables, caricatures) or verbal aids facilitating understanding of the production of demanding operations?

Focusing on academic functions, anticipating and taking into account potential difficulties will not only facilitate learners' access to disciplinary knowledge but also help them understand what is expected of them, what they must do and what language means are the most suitable. This does not mean that the teacher of a subject has to become a language teacher, but he or she should be sensitive to the many aspects of integrating language content into learning (Vollmer, 2009). In short, second-language discipline teaching cannot do without planning and controlling communication.

\section{Conclusion}

The two functions of language evoked show the close interdependence of disciplinary knowledge and language. The social function of transmitting knowledge of language is now universally accepted in the scientific community: knowledge is acquired through participation in mediated experiences in communication with an expert. The acquisition of language and the acquisition of disciplinary knowledge are, however, treated as two distinct domains, as if thought were a purely mental object without a necessary relation to language. This so-called intellectualist approach considers that the mind represents the objects of the world from which ideas emerge that combine with each other. It forms some ideas and combines these ideas together. He then uses words to express or communicate his thoughts. The words would then be only the clothes of thought and they would be only a means of making it known and communicating it.

The epistemic function is based on the hypothesis that language is not reduced to giving an external form to thought, but is a tool for training and developing thoughts. The linguistic signs do not only allow the communication, they ensure the abstraction, the generalization, the categorization as well as the systematization of the meanings. They are used by the brain to organize units of thought or to create a system of relationships on which new forms of analogy and synthesis are based (Jeuk, 2011). In other words, language accomplishes a real cognitive function in the construction of knowledge. It is therefore not enough, like the CLIL approach (Content and Language Integrated Learning) to postulate the taking into account of the appropriation of the language during the disciplinary learning since the disciplinary learning and the apprenticeship linguistics are apprehended separately. On the contrary, these two processes are based on a unique mechanism: language learning is involved in learning specific knowledge. Language belongs to cognition. It is therefore subject to its rules of operation. Research must show the way in which language and 
knowledge are mutually constituted in a unified socio-cognitive approach to the acquisition of disciplinary and linguistic knowledge.

\section{References}

Bailey, A. L., \& Heritage, H. M. (2008). Formative assessment for literacy, grades K-6: Building reading and academic language skills across the curriculum. Thousand Oaks: CA: Corxin Press.

Becker-Mrotzek, M., \& Vogt, R. (2009). Teaching communication. Linguistic analysis methods and research results. Tübingen: Max Niemeyer Verlag.

Cassirer, E. (1922). The concept of symbolic form in the construction of the sciences of the spirit. Three essays on the symbolic (Works VI). Paris: The Deer.

Cassirers, E. (1923). Philosophy of symbolism for men. Berlin: Bruno Cassirer Verlag.

Hallet, W. (2013). Generic learning in specialized education. In Becker-Mrotzek, M., Schramm, K., Thürmann, E., Vollmer, J.H. (Eds.). Language in the subject. Münster: Publisher Waxmann.

Hammond, J., \& Gibbons, P. (2001). What is scaffolding? In Hammond, J. (ed.). Teaching and Learning in Language and Literacy Education. Newton. Australia: Primary English Teaching Association.

Handro, S. (2013). Language and historical learning. Dimensions of a key problem of history teaching. In Becker-Mrotzek, M., Schramm, K., Thürmann, E., Vollmer, J.H. (Eds.). Language in the subject. Linguistic and technical learning. Münster: Waxmann.

Jeismann, K.-E. (1978). Didactics of the story. The specific condition field of history teaching. In Behrmann, G., Jeismann, K.-E., Suessmuth, H. (ed.). History and politics. Didactic foundation of a cooperative lesson. Paderborn: Schöningh.

Jeuk, S. (2011). First steps in the second language German. Freiburg im Breisgau: Fillibach-Verlag.

Kant, I. (1781). The critique of pure reason. Riga: J.F. Hartknoch.

Krashen, S. (1977). Some issues relating to the monitor model. In Brown, H., Yorio, C., Crymes, R. (Eds.). In TESOL 77 (pp. 144-158). Washington D.C Teachers of English to Speakers of Other Languages.

Krashenp, S. (1981). Second language acquisition and second language learning. Oxford, New York, Toronto: Pergamon.

Krashens, S. (1978). Individual variation in the use of the monitor. In Ritchie, W. (ed.). Second Language Acquisition Research (pp. 175-183). New York: Academic Press.

Leinfellner, W. (1965). Introduction to the theory of knowledge and science. Mannheim: Bibliographic Institute.

Long, M. (1981). Questions in foreigner talk discourse. Language Learning, 31(1), 135-157. Available at: 10.1111/ j.14671770.1981.tbo1376.x

Longp, M. (1985). A role for instruction in second language acquisition: task-based language teaching. In Hyltenstam, K., Pienemann, M. Modeling and Assessing Second Language Acquisition. Clevedon, Avon: Multilingual Matters.

Longs, M. (1983). Does second language instruction make a difference? A review of the research. TESOL Quaterly, 17(3), 359-382. Available at: 10.2307/3586253.

Scarcella, R. (2008). Academic language: Clarifying terms. Accelerate! The Quarterly Newesletter of the National Clearinghouse for English Language Acquisition, 1(1), 5-6.

Sensevy, G., \& Mercier, A. (2007). Acting together: Elements of theorizing the joint action of the teacher and the students. Rennes: University Presses of Rennes.

Sfard, A. (2000). Symbolizing mathematical reality in being: How mathematical discourse and mathematical objects create each other. In Cobb, P., Yackel, K.E., McClain, K. (eds.). Symbolizing and communicating: perspectives on Mathematical Discourse, Tools, and Instructional Design. Mahwah, NJ: Erlbaum.

Slobin, D. I. (2003). Language and thought online: Cognitive consequences of linguistic relativity. In Gentner, D., Goldin-Meadow, S. Language in Mind. Cambridge: The MIT Press.

Swain, M. (1985). Communicative competence: Some roles of comprehensible input and comprehensible output in its development. In Gass, S., Madden, C. (eds). Input in the second language classroom. Rowley, MA: Newbury House.

Swains, M. (1995). Three functions of output in second language learning. In Cook, G., Seidlhofer, B. (eds). Principle and practice in applied linguistics. Studies in honor of H. G. Widdowson. Oxford: Oxford University Press.

Verret, M. (1975). The time of studies. Paris: Honoré Champion Bookstore.

Vollmer, H. J. (2009). Language (s) from other disciplines. Strasbourg: Council of Europe. Retrieved from www.coe.int/lang. 